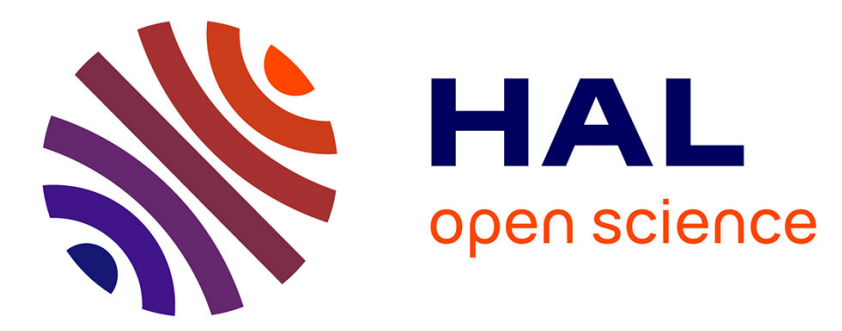

\title{
OMEGA/Mars Express: South Pole Region, water vapor daily variability
}

\author{
R. Melchiorri, T. Encrenaz, P. Drossart, T. Fouchet, F. Forget, D. Titov, L. \\ Maltagliati, F. Altieri, M. Vincendon, Y. Langevin, et al.
}

\section{- To cite this version:}

R. Melchiorri, T. Encrenaz, P. Drossart, T. Fouchet, F. Forget, et al.. OMEGA/Mars Express: South Pole Region, water vapor daily variability. Icarus, 2009, 201 (1), pp.102. 10.1016/j.icarus.2008.12.018 . hal-00524849

\section{HAL Id: hal-00524849 \\ https://hal.science/hal-00524849}

Submitted on 9 Oct 2010

HAL is a multi-disciplinary open access archive for the deposit and dissemination of scientific research documents, whether they are published or not. The documents may come from teaching and research institutions in France or abroad, or from public or private research centers.
L'archive ouverte pluridisciplinaire HAL, est destinée au dépôt et à la diffusion de documents scientifiques de niveau recherche, publiés ou non, émanant des établissements d'enseignement et de recherche français ou étrangers, des laboratoires publics ou privés. 


\section{Accepted Manuscript}

OMEGA/Mars Express: South Pole Region, water vapor daily variability

R. Melchiorri, T. Encrenaz, P. Drossart, T. Fouchet, F. Forget, D. Titov, L. Maltagliati, F. Altieri, M. Vincendon, Y. Langevin, J.P. Bibring

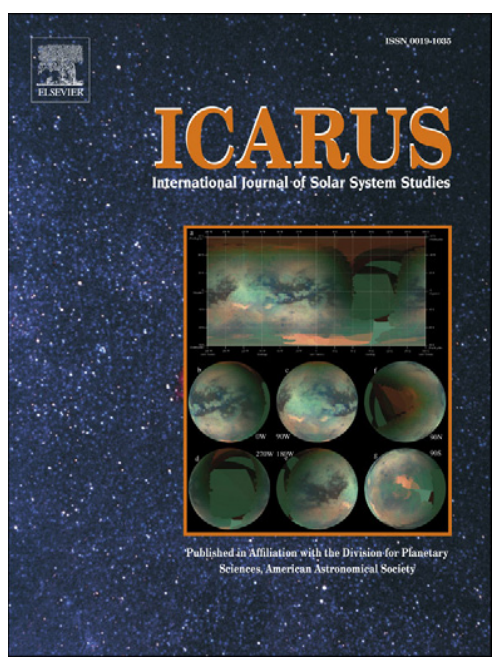

PII: $\quad$ S0019-1035(08)00446-6

DOI: $\quad$ 10.1016/j.icarus.2008.12.018

Reference: $\quad$ YICAR 8856

To appear in: Icarus

Received date: 12 February 2008

Revised date: 9 December 2008

Accepted date: 11 December 2008

Please cite this article as: R. Melchiorri, T. Encrenaz, P. Drossart, T. Fouchet, F. Forget, D. Titov, L. Maltagliati, F. Altieri, M. Vincendon, Y. Langevin, J.P. Bibring, OMEGA/Mars Express: South Pole Region, water vapor daily variability, Icarus (2009), doi: 10.1016/j.icarus.2008.12.018

This is a PDF file of an unedited manuscript that has been accepted for publication. As a service to our customers we are providing this early version of the manuscript. The manuscript will undergo copyediting, typesetting, and review of the resulting proof before it is published in its final form. Please note that during the production process errors may be discovered which could affect the content, and all legal disclaimers that apply to the journal pertain. 


\title{
OMEGA/Mars Express: South Pole Region, water vapor daily variability
}

\author{
R.Melchiorri ${ }^{\mathrm{a}, \mathrm{b}}$, T. Encrenaz ${ }^{\mathrm{a}}$, P. Drossart ${ }^{\mathrm{a}}$, T. Fouchet ${ }^{\mathrm{a}}$, \\ F. Forget ${ }^{c}$, D. Titov ${ }^{\text {d }}$, L. Maltagliati ${ }^{d}$, F. Altieri ${ }^{\mathrm{e}}$, \\ M. Vincendon ${ }^{\text {f }}$, Y. Langevin ${ }^{\mathrm{f}}$, J.P. Bibring ${ }^{\mathrm{f}}$, \\ ${ }^{a}$ LESIA, Observatoire de Paris section de Meudon, FRANCE \\ ${ }^{\mathrm{b}}$ ORAU NASA postdoctoral program at AMES Research Center, Moffet Field, \\ California, USA \\ ${ }^{\mathrm{c}}$ Laboratoire de Métheorologie dynamique, Paris FRANCE \\ d Max Planck Institut for Solar System Research, Katlenburg-Lindau, GERMANY \\ ${ }^{\mathrm{e}}$ Istituto di Fisica dello Spazio e del mezzo Interstellare, Roma, ITALY \\ ${ }^{\mathrm{f}}$ Institut d'Astrophysique Spatial, Orsay, FRANCE
}

\section{ABSTRACT}

Polar regions on Mars are the most suitable places to observe water vapor daily variability because in any observation crossing the Pole we can observe very different local time and because the poles are considered to be the main permanent and seasonal water reservoir of the planet.

We report on a daily variability of water vapor in the south pole region (SPR), observed by OMEGA/Mars Express during the south spring-summer period $\left(\mathrm{Ls} \sim 250^{\circ}-270^{\circ}\right)$ outside the $\mathrm{CO}_{2}$ ice cap, that has never been observed before by other instruments. We have been able to estimate an increase of few precipitable microns during the day.

A possible scenario includes the presence of regolith, or another component that could gather water from the atmosphere, adsorbing the water into the surface during the night time and desorbing it as soon as the sun reaches sufficient height to heat the ground. This hypothesis is even more plausible considering the presence of observed local enhancements in the morning sections associated with the illumination of the Sun and the 
total absence in the data for water ice.

Number of pages: 13

Number of tables: ??

Number of figures: 16 
Proposed Running Head:

Daily variability of water vapor in the south pole region

Please send Editorial Correspondence to:

Riccardo MELCHIORRI

NASA/ Ames Research Center

MS 245-3

Moffet Field CA USA 94035

Email: riccardo.melchiorri-1@nasa.gov

Phone: (001) 6506041488 


\begin{abstract}
Polar regions on Mars are the most suitable places to observe water vapor daily variability because in any observation crossing the Pole we can observe very different local time and because the poles are considered to be the main water reservoir of the planet.

We report on a daily variability of water vapor in the south pole region (SPR), observed by OMEGA/Mars Express during the south spring-summer period $\left(\operatorname{Ls} \sim 250^{\circ}-270^{\circ}\right)$ outside the $\mathrm{CO}_{2}$ ice cap, that has never been observed before by other instruments. We have been able to estimate an increase of few precipitable microns during the day.

A possible scenario includes the presence of regolith, or another component that could gather water from the atmosphere, adsorbing the water into the surface during the night time and desorbing it as soon as the sun reaches sufficient height to heat the ground. This hypothesis is even more plausible considering the presence of observed local enhancements in the morning sections associated with the illumination of the Sun and the total absence in the data of water ice.
\end{abstract}

Keywords: OMEGA ; Mars Express ; Satellite ; Image Spectroscopy http://icarus . cornell . edu/: 


\section{Introduction}

The Martian water cycle is one of the main cycles that control the Martian atmosphere. Recent observations have shown a highly spatial and temporal variability (Fedorova et al. (2006); Sprague et al. (2006); Encrenaz et al. (2005)), especially concerning the Polar Regions (Melchiorri et al., 2007). It is not yet clear in which proportion these variabilities are locally produced or if they are redistributed dynamically in/by the atmosphere.

The water vapor abundance is strongly correlated with the temperature cycle (Böttger et al., 2005), therefore a maximum during the day and a minimum at night time and in the early morning occur. It has been suggested that this is a signature of regolith "breathing" forced by the change in temperature (Titov, 2002). Regolith-atmosphere water exchange was also proposed as a mechanism to explain water enhancement above Tharsis volcanoes observed by ISM/Phobos experiment (Titov et al., 1994).

Models have been developed to study the adsorption of water onto regolith grains (Zent et al. (1993); Zent and Quinn (1997); Houben et al. (1997)). In particular Zent et al. (1993) used a basalt regolith model to show that daily "breathing" of the regolith altered the column water vapor abundance by $\sim 1$ pr- $\mu \mathrm{m}$. But different materials could introduce a stronger effect.

Nevertheless recent works (Maltagliati et al. (2008); Montmessin et al. (2004); Richardson et al. (2002)) show that models and observations are not in agreement and that other phenomena than the regolith should be taken into account.

Other phenomena could help in explaining this variability as the formation of night time hazes, which removes some water vapor from the night time column, but calculations have shown (Jakosky, 1985) that the fog can only account for a small amount of the water vapor removed. Frost observed at the surface of the Viking 2 landing site, which forms during the night time, will also reduce the vapor column further (Jones et al., 1979).

The water vapor is then an important factor in understanding the exchange of the atmosphere with the surface and subsurface reservoirs on several timescales, as well as, the transport of water within the atmosphere (Houben et al., 1997)

Data from different space missions are now available but only few of them allow a daily variability analysis. The Sun synchronous orbit of MGS does not allow this kind of study, although TES limb data may provide some information for the middle-upper atmosphere (Houben, 1999). The Mars Atmospheric water Detector (MAWD) has provided evidence of a daily variability (Jakosky et al., 1988). The Infrared Imaging Spectrometer (ISM) on board of the Pho- 
bos II mission has shown a variability in water vapor abundance between morning and noon of a factor of 2-3 in the Pavonis Mons region (Titov, 1997); a re-analysis of the IRIS/Mariner-9 data set by Formisano et al. (2001) also indicated a variability in day/night time water vapor abundance of about a factor of two, combined with an anti-correlation with dust opacity. These together with ground-based observations by Sprague et al. (1996); Hunten et al. (2000) and Imager for Mars Pathfinder (IMP) data (Titov et al., 1999) indicate a strong variability in column water vapor abundance during the course of a day.

The geometry of the Mars Express orbits in general does not allow to observe daily time variability, since the nadir observations are always over a restricted range of longitudes, but when the orbit pass over the poles we observe very different local times in a single observation. The poles are then the most suitable places to observe a daily variability, allowing a better understanding of interaction between the atmosphere and the regolith, revealing also the presence of sources and sinks of water vapor.

We report on the latest results obtained with OMEGA/Mars Express (Bibring et al., 2004) by analyzing data during the period Ls $250^{\circ}-280^{\circ}$ over the South Pole. This period and region is characterized by a receding $\mathrm{CO}_{2}$ ice cap; no water ice detected by OMEGA on the surface (Langevin et al., 2007); a nonsignificant presence of haze or fog; a Pole always illuminated by the Sun up to a latitude of $70^{\circ} \mathrm{S}$ (but with different incidence angles); a maximum of water vapor (30 ppt- $\mu \mathrm{m}$; Fig. 1) due to the South Summer sublimation.

These data are of particular interest because a condensation of the water vapor is expected to be seen during the "night" (Fig. 2), following the temperatures and pressures retrieved by the EMCD (Forget et al., 1999). Although no water ice is detected on the ground, nor is fog observed. Moreover some of the "morning" sections show specific and local regions of enhancement of water vapor suggesting an interaction of the atmosphere with the ice possibly present a few centimeters below the surface (Boynton et al., 2002).

\section{OMEGA observations}

The Mars Express spacecraft was launched by ESA on June 2, 2003, and has been operating in orbit around Mars since January 2004. The orbit is almost polar and highly elliptical, with a period close to $7 \mathrm{~h}$.

The OMEGA instrument is an imaging spectrometer operating in the visible and near-infrared range, from $0.35 \mu \mathrm{m}$ to $5.1 \mu \mathrm{m}$, with a spectral resolution of $7 \mathrm{~nm}$ below $1 \mu \mathrm{m}, 14 \mathrm{~nm}$ in the 1.0-2.5 $\mu \mathrm{m}$ range, and $20 \mathrm{~nm}$ above $2.5 \mu \mathrm{m}$. 
With an instantaneous field of view (IFOV) of $1.2 \mathrm{mrad}$, its spatial resolution at the surface of Mars ranges from about $300 \mathrm{~m}$ (close to periapsis) up to 4.8 $\mathrm{km}$ from an altitude of $4000 \mathrm{~km}$. In order to have a continuous coverage during an orbit, the longitudinal width varies from 16 to 128 IFOV, depending on the distance and on the speed of the instrument from the surface.

Orbits are identified by labels like: xxxx-y, where y is the "section" of the "orbit" x.

All orbits used are at nadir: emission angle around $0^{\circ}$. This implies that the phase angle depends mainly on the incidence angle. All data have been calibrated using the SOFT04 procedures provided by the IAS (Institut d'Astrophysique Spatiale, Orsay), which includes the detection of dead or hot pixels systematically excluded from our calculations. We have selected the period from Ls $250^{\circ}$ to $280^{\circ}$ in the South Polar Region (end of south spring - summer), which correspond to the OMEGA orbits from 1927 to 2094.

The South Polar Region (defined by latitudes higher than $60^{\circ} \mathrm{S}$; SPR) in summer is always illuminated by the Sun (Fig. 3), but with different incidence angles. Local time differ physically from the incidence angle because morning and evening sections have different total quantity of heat transferred to the ground from the Sun but have similar incidence angles. We identify the morning as the period where incidence angle is high $\left(\sim 90^{\circ}\right)$ and decreases. In order to discriminate between morning and evening we define the morning incidence angles as negative.

The south summer is characterized by the presence of a maximum of water vapor ( Fedorova et al. (2006); Melchiorri et al. (2007); Sprague et al. (2006)); Smith (2002)) which is supposed to be produced by the sublimation of the water ice in the SPR.

All water vapor data presented here are in ppt- $\mu \mathrm{m}$ and are normalized to the pressure at 6.1 mbar. The albedo maps have been retrieved using the $1.3 \mu \mathrm{m}$ band (Pelkey et al., 2007) and normalized by the cosine of the incidence angle.

Since the data are normalized to the pressure we expect no variability of the water vapor as a function of the pressure. Since both the $2.0 \mu \mathrm{m} \mathrm{CO}_{2}$ band and the $2.6 \mu \mathrm{m}$ water vapor band depend on pressure, an error in measuring the pressure would lead to a residual dependence of the water vapor on the pressure itself (Fig.4). To verify that the retrieved daily variability is not associated with the daily variability of the pressure we have traced the values of the water vapor as a function of the pressure (Fig.4). In the range between 7-10 mbar and 5-20 ppt- $\mu \mathrm{m}$ the distribution is constant between the error bars. Values outside this range must be considered contaminated by $\mathrm{CO}_{2}$ ice, which affects both bands. Increasing the water vapor does not lead to an increase of pressure, this demonstrate that the increase of water vapor detected is not 
associated with a pressure variability.

\section{3 water vapor Retrieval Method}

We have developed a fast algorithm to retrieve the total quantity of water vapor from the OMEGA / Mars Express data (Melchiorri et al. (2007); Encrenaz et al. (2005)). It is based on the principle that water partial pressure, for a given surface pressure, is a known function of the band depth, which can be estimated from a set of curves of growth. By analyzing the $2.6 \mu \mathrm{m}$ water band we have extracted from the entire OMEGA database the water vapor information (Fig.5).

For general purposes the ground pressure value can be retrieved through the EMCD (European Mars Climate Database, v 4.3) high resolution surface pressure predictor "pres0" described in Forget et al. (2007). However, we found that the actual pressure was subject to a large variability which was not easy to capture from the model. Alternatively, we chose to retrieve the ground pressure through the analysis of the $1.43 \mu \mathrm{m} \mathrm{CO}_{2}$ band depth (Fig. 6). Although this measurement might not be very accurate in absolute value, it suited our need to follow the actual day to day variations (Fig. 7). The reason for the difference between the observation and the model is still to be defined and studied, nevertheless since the albedo variability is not correlated with it, scattering influence should be neglectable.

In Fig 8 the water vapor has been plotted as a function of the incidence angle. Negative value of the angle indicate a morning value. It possible to observe that for all the three periods the water vapor value increases following the incidence angle from -90 to +90 . Which means that for equal values of incidence angle, in the morning and in the evening, we have different values of water vapor, which implies a non correlation.

Light scattered by aerosols significantly impact observations of Mars made in the near-IR (Erard et al., 1994). We have checked that our water vapor variability is not due to aerosols using two different approaches. First, we have looked for correlation between retrieved water vapor values and solar incidence angle. The path length of photons in the layer of aerosols increases with incidence angle. Scatter plots between water vapor and incidence angle are shown in Fig. 8. The water vapor abundance increases following the incidence angle from -90 to +90 for the three periods (Ls 250, 260 and 270). That is to say, we have different values of water vapor for equal values of the incidence angle in the morning and in the evening, which implies a non-correlation. Secondly, we have looked for correlations between retrieved water vapor values and observed albedo. Recent studies have shown that the optical depth of aerosols 
in the southern polar regions can change by a factor of 3 in one day around summer solstice (Vincendon et al., 2008). Such a change can be detected by an increase of the apparent albedo of dark regions. Significant increases in the $2.6 \mu \mathrm{m}$ band depth occurs between morning and evening observations without change in the apparent albedo of dark regions (e.g. for orbits 1962_1 and 1967_2, Fig.9).

As in our previous analysis (Encrenaz et al. (2005); Melchiorri et al. (2007)), in order to ensure the detection we have divided the entire data-set by a reference spectrum (named "volcano scan", one for each type of calibration), which allows suppression of un-calibrated residual from the instrument. Nonlinearity is already taken into account by the SOFT04 software.

The water vapor retrieval method has a few known limitations. First, if the water vapor is confined in a layer instead of being well mixed in the air as assumed (in case of condensation or out-gassing), the error bar can be increased. Second, small grains of water ice present a bump in the spectrum at $2.6 \mu \mathrm{m}$ which influences our method by lowering the detected water vapor value (Fig. 10). Third, the broad $\mathrm{CO}_{2}$ ice $2.7 \mu \mathrm{m}$ band alters the continuum of the band and makes our method overestimate the real water vapor quantity. For these reasons, regions covered by $\mathrm{CO}_{2}$ ice are not included in our calculations (Fig. 11) and regions covered by water ice are closely examined (Melchiorri et al., 2007).

$\mathrm{CO}_{2}$ ice detection is possible through the study of the $3.0 \mu \mathrm{m}$ band (Langevin et al., 2007). An analysis of the band depth shows that a clear detection is possible for band depth values higher than $8 \%$. We assume this as our threshold detection. However, for safety, all regions with more than $30 \mathrm{ppt}-\mu \mathrm{m}$ in this work have been removed as potentially contaminated by $\mathrm{CO}_{2}$ ice, knowing that it is a strong constraint. This limit should not be applied to regions or periods other than in this work.

\section{Daily variability}

The selected OMEGA data-set has been divided into three periods (Ls $=250^{\circ}$ $259^{\circ}, 260^{\circ}-269^{\circ}$ and $270^{\circ}-279^{\circ}$ ).

Analyzing the data we may assume with a good approximation that inside the SPR (latitudes lower than 60.S) different regions should behave in a similar way as a function of local time.

In Fig.12, 13 and 14 the distribution of the different observed values of water vapor and albedos at different locations and time in the SPR is shown as 
a function of local time. In all the three periods albedo presents a slightly constant value over local time (with some small change in the early morning or late afternoon), which implies that scattering is not a main protagonist of the daily variability.

The water vapor can be identified in three different groups:

(1) values ranging between 0 and 15 ppt- $\mu \mathrm{m}$

(2) values around $30 \mathrm{ppt}-\mu \mathrm{m}$

(3) values above $30 \mathrm{ppt}-\mu \mathrm{m}$

The first group presents in the first two selected periods $\left(\mathrm{Ls}=250^{\circ}\right.$ and $\left.260^{\circ}\right)$ a clear daily variability. We can observe an increase of the water vapor from $5 \mathrm{am}$ $(2 \mathrm{ppt}-\mu \mathrm{m})$ to $4 \mathrm{pm}(10 \mathrm{ppt}-\mu \mathrm{m})$. Low values are present in the early morning but disappear between 5am (lower than 2ppt- $\mu \mathrm{m}$ ) and 4pm (lower than 4ppt$\mu \mathrm{m})$. Concerning $\mathrm{Ls}=270^{\circ}$, values seems to be more constant and spread which makes it impossible to state if there is or not an increase of water vapor between $5 \mathrm{am}$ and $3 \mathrm{pm}$, nevertheless there are only few values lower than few ppt- $\mu \mathrm{m}$ in the middle of the day.

The second group seems to be correlated with regions close to the ice cap, but still ice free (at the OMEGA resolution; spatial and spectral). It appears mostly in the middle of the day (7am - 1pm) and it is mainly constant over time.

The third group should not be considered as water vapor because, as mentioned above, the data can be potentially contaminated with $\mathrm{CO}_{2}$ ice.

Data outside the selected period (before $\mathrm{Ls}_{\mathrm{S}}=250^{\circ}$ and after $270^{\circ}$ ) do not present strong evidence of a daily variability (as the one presented in this work), further studies will be conducted to determine if daily variability may occur (and can be detected) on the North Pole or in the equatorial region, too.

\section{Close up on morning section}

The presence of water ice in beneath the $\mathrm{CO}_{2}$ ice cap has been recently reported by Bibring et al. (2004); Langevin et al. (2007), these works show how water ice disappears from the surface of the ice cap $\left(\mathrm{Ls}=247^{\circ}\right)$ and reappear $\operatorname{after}\left(\mathrm{Ls}=275^{\circ}\right)$. Even though our water vapor retrieval method in not appropriate on the $\mathrm{CO}_{2}$ ice cap, we detect a strong enhancement on the boundary of the $\mathrm{CO}_{2}$ ice cap, higher than 30ppt- $\mu \mathrm{m}$, which could be associated with the sublimation of the water ice present in the $\mathrm{CO}_{2}$ ice cap. Unfortunately we 
cannot ensure that these results are not partially contaminated by residual $\mathrm{CO}_{2}$ ice, which false increase the derived value, as previously explained.

The water vapor spatial distribution in every afternoon section is more homogeneous than in the morning; it also presents higher values (up to $15 \mathrm{ppt}-\mu \mathrm{m}$ ). Spatial uniformity suggests that water would appear from the surface rather than from the ice cap. If the polar cap would have been the only source we would have seen an $\mathrm{H}_{2} \mathrm{O}$ gradient moving out from the ice cap, which is not the case. Moreover in some of the morning sections we have detected, outside the ice cap but still in SPR, well-defined regions with a "snake" like form of water vapor enhancement. One example is shown in fig.15 for the orbit 1983_1 $\left(\mathrm{Ls}=260^{\circ}\right)$.

The enhancement seems to be partially following the altimetry slope, but it is not correlated with; it is well-correlated with the boundary between dark/bright regions (in the albedo image).

Comparing the spectra we can state that the dark and bright regions present similar spectral features. In Fig. 16 it is possible to compare the mean spectra extracted from these three regions (high, low albedo and water vapor enhancement). The spectrum of the water vapor region is characterized by a continuum (spectra have not been corrected by the incidence angle) in between the other regions and by a stronger $2.6 \mu \mathrm{m}$ band. This enhancement seems to be associated with illumination: regions on the right are illuminated with higher incidence angles and have lower ground temperatures.

It is clear that the water vapor follows the contour of the albedo. Moreover the snake like feature mainly follows a constant incidence angle $\left(\sim 66^{\circ}\right)$.

All these data suggest the presence of water ice on the ground that immediately sublimes as soon as the ground temperature rise above the sublimation point. Nevertheless no water ice is detected on the surface by OMEGA.

\section{Conclusion}

In the period between $\mathrm{Ls}=250^{\circ}$ and Ls $270^{\circ}$ we could expect to observe a condensation of the water vapor during the night time and a sublimation during the day time, since the temperature and the pressure are close to saturation. However no water ice is detected by OMEGA in this period outside and on the ice cap (Langevin et al., 2007). Nevertheless we detect a variability of water vapor with a sensitive difference between morning and evening. This variability is not associated with scattering (clouds, haze or fog) or correlated with the incidence angle. 
In the evening the water vapor presents a quite homogeneous horizontal distribution, which suggest that water vapor has been locally produced rather than been driven by the atmosphere from elsewhere. If the water vapor is produced by the South Pole cap there would be a radial distribution emanating from the ice cap, which is not the case.

water vapor derived with our method distributes over three main groups of values: a wide spread group (from 0 to $15 \mathrm{ppt}-\mu \mathrm{m}$ ), a localized range group (around $30 \mathrm{ppt}-\mu \mathrm{m}$ ) and a high value group (over $30 \mathrm{ppt}-\mu \mathrm{m}$ ).

The first group is the main protagonist of the daily variability. It presents an heterogeneous spatial distribution of values ranging from 0 to $15 \mathrm{ppt}-\mu \mathrm{m}$.

It is important to underline that the water vapor distribution in the morning (histograms in the Fig. 12, 13 and 14) does not follow a Gaussian distribution. If one would have to determine the error bar of the mean value it would most probably retrieve a value of the standard deviation of $\sim 10-15 \mathrm{ppt}-\mu \mathrm{m}$ (forcing the assumption of a Gaussian distribution). It is instead clear that the distribution of water vapor values is composed of several Gaussian (at least). In particular it is noticeable that the presence of a 3ppt- $\mu \mathrm{m}$ peak early in the morning disappears in the afternoon. This implies that the water vapor values become more homogeneous in the afternoon distributing in a more Gaussian like distribution. The detected daily variability is associated more with this change than with an increase of the mean value itself. For this reason we can state that the error bar associeted with the daily variability is around $\sim 3$ ppt$\mu \mathrm{m}$, which is the threshold of detection of the low values in the distribution.

The second group appears only in the middle of the day and is associated often with regions close to the ice cap, this could be due to a release of water from the ice cap. Nevertheless the proximity of these values to the ice cap does not allow us to clearly state if these values are due to the water vapor only or if a small amount of $\mathrm{CO}_{2}$ ice contaminates our results. For sake of the result, the error bar should than be considered larger $\sim 10 \mathrm{ppt}-\mu \mathrm{m}$ to ensure the detection.

The third group is associated with the ice cap region itself and should not be taken as water vapor because of the $\mathrm{CO}_{2}$ ice contamination of the spectra. Nevertheless it is noticeable that in the boundaries of the ice cap we observe higher values of water vapor which could be due to water vapor degassing from the ice cap itself, nevertheless at the state of the study we cannot affirm if this enhancement is due entirely to $\mathrm{CO}_{2}$ ice or to water vapor.

If water vapor condenses on the ground, it should be detectable by OMEGA unless it has been absorbed/adsorbed (by regolith for example) or moved away from the SPR by some dynamic in only few hours. 
The presence of local enhancements of water vapor associated with the illumination allows us to propose that the region surrounding the $\mathrm{CO}_{2}$ ice cap could be a secondary source or sink of water vapor. Nevertheless the quantity of water "captured" by the ground cannot be quantified in this work and we cannot affirm if this phenomenon is or is not associated with the ice possibly present a few centimeters below the surface (Boynton et al., 2002) or even with huge deep polar cap reservoir (Plaut et al., 2007).

Further studies should be foreseen in association with models to establish if the regolith can be responsible for this variability or if other capturing mechanisms should be considered.

\section{Acknowledgements}

This research was supported also by an appointment to the NASA Postdoctoral Program at the (NASA/Ames Research Center), administered by Oak Ridge Associated Universities through a contract with NASA.

\section{References}

J-P Bibring, A. Soufflot, M. Berth, Y. Langevin, B. Gondet, P. Drossart, M. Bouy, M. Combes, P. Puget, A. Semery, G. Bellucci, V. Formisano, V. Moroz, V. Kottsov, and OMEGA Co-I team. The Mars Express Mission: An Overview. ESA SP, 1240, 2004.

H. M. Böttger, S. R. Lewis, P. L. Read, and F. Forget. The effects of the martian regolith on GCM water cycle simulations. Icarus, 177:174-189, September 2005. doi: 10.1016/j.icarus.2005.02.024.

W. V. Boynton, W. C. Feldman, S. W. Squyres, T. H. Prettyman, J. Brückner, L. G. Evans, R. C. Reedy, R. Starr, J. R. Arnold, D. M. Drake, P. A. J. Englert, A. E. Metzger, I. Mitrofanov, J. I. Trombka, C. d'Uston, H. Wänke, O. Gasnault, D. K. Hamara, D. M. Janes, R. L. Marcialis, S. Maurice, I. Mikheeva, G. J. Taylor, R. Tokar, and C. Shinohara. Distribution of Hydrogen in the Near Surface of Mars: Evidence for Subsurface Ice Deposits. Science, 297:81-85, July 2002.

S. Dout, B. Schmitt, Y. Langevin, J.-P. Bibring, F. Altieri, G. Bellucci, B. Gondet, F. Poulet, and the MEX OMEGA team. South Pole of Mars: Nature and composition of the icy terrains from Mars Express OMEGA observations. planss, 55:113-133, January 2007.

T. Encrenaz, R. Melchiorri, T. Fouchet, P. Drossart, E. Lellouch, B. Gondet, J.-P. Bibring, Y. Langevin, D. Titov, N. Ignatiev, and F. Forget. A mapping of martian water sublimation during early northern summer using 
OMEGA/Mars Express. aap, 441:L9-L12, October 2005. doi: 10.1051/00046361:200500171.

S. Erard, J. Mustard, S. Murchie, J.-P. Bibring, P. Cerroni, and A. Caradini. Martian aerosols: Near-infrared spectral properties and effects on the observation of the surface. Icarus, 111:317-337, October 1994. doi: 10.1006/icar.1994.1148.

A. Fedorova, O. Korablev, J.-L. Bertaux, A. Rodin, A. Kiselev, and S. Perrier. Mars water vapor abundance from SPICAM IR spectrometer: Seasonal and geographic distributions. Journal of Geophysical Research (Planets), 111 (E10):9-+, September 2006. doi: 10.1029/2006JE002695.

F. Forget, F. Hourdin, R. Fournier, C. Hourdin, O. Talagrand, M. Collins, S. R. Lewis, P. L. Read, and J. Huot. Improved general circulation models of the Martian atmosphere from the surface to above $80 \mathrm{~km}$. jgr, 104(13): 24155-24176, October 1999.

F. Forget, A. Spiga, B. Dolla, S. Vinatier, R. Melchiorri, P. Drossart, A. Gendrin, J.-P. Bibring, Y. Langevin, and B. Gondet. Remote sensing of surface pressure on Mars with the Mars Express/OMEGA spectrometer: 1. Retrieval method. Journal of Geophysical Research (Planets), 112(11):8-+, August 2007. doi: 10.1029/2006JE002871.

V. Formisano, D. Grassi, N. I. Ignatiev, and L. Zasova. IRIS Mariner 9 data revisited: water and dust daily cycles. planss, 49:1331-1346, November 2001.

H. Houben. The Martian diurnal water cycle. Advances in Space Research, 23:1587-1590, 1999.

H. Houben, R.M. Haberle, R.E. Young, and A.P. Zent. Modelling the martian seasonal water cycle. JGR, 102:9069-9083, 1997.

D. M. Hunten, A. L. Sprague, and L. R. Doose. Correction for Dust Opacity of Martian Atmospheric Water Vapor Abundances. Icarus, 147:42-48, September 2000. doi: 10.1006/icar.2000.6423.

B. M. Jakosky, R. W. Zurek, and M. R. La Pointe. The observed day-today variability of Mars atmospheric water vapor. Icarus, 73:80-90, January 1988. doi: 10.1016/0019-1035(88)90086-3.

B.M. Jakosky. The seasonal cycle of water on Mars. Space SCI. Rev., 41: 131-200, 1985.

K.L Jones, R.E. Arvidson, E.A. Guiness, S.L. Bragg, S.D. Wall, C.E. Carlston, and D.G. Pidek. One Mars year: Viking lander imaging. Science, 204:799806, 1979.

Y. Langevin, J.P. Bibring, F. Montmessin, F. Forget, M. Vincendon, S. Dout, F. Poulet, and B. Gondet. Observations of the south seasonal cap of Mars during recession in 2004-2006 by the OMEGA visible/near-infrared imaging spectrometer on board Mars Express. jgr, 112(13):24155-24176, July 2007.

L. Maltagliati, D. V. Titov, T. Encrenaz, R. Melchiorri, F. Forget, M. GarciaComas, H. U. Keller, Y. Langevin, and J.-P. Bibring. Observations of atmospheric water vapor above the Tharsis volcanoes on Mars with the OMEGA/MEx imaging spectrometer. Icarus, 194:53-64, March 2008. doi: 10.1016/j.icarus.2007.09.027. 
R. Melchiorri, T. Encrenaz, T. Fouchet, P. Drossart, E. Lellouch, B. Gondet, J.-P. Bibring, Y. Langevin, B. Schmitt, D. Titov, and N. Ignatiev. Water vapor mapping on Mars using OMEGA/Mars Express. planss, 55:333-342, February 2007. doi: 10.1016/j.pss.2006.05.040.

F. Montmessin, F. Forget, P. Rannou, M. Cabane, and R. M. Haberle. Origin and role of water ice clouds in the Martian water cycle as inferred from a general circulation model. Journal of Geophysical Research (Planets), 109 (18):10004-+, October 2004. doi: 10.1029/2004JE002284.

S. M. Pelkey, J. F. Mustard, S. Murchie, R. T. Clancy, M. Wolff, M. Smith, R. Milliken, J.-P. Bibring, A. Gendrin, F. Poulet, Y. Langevin, and B. Gondet. CRISM multispectral summary products: Parameterizing mineral diversity on Mars from reflectance. Journal of Geophysical Research (Planets), 112(11):8-+, July 2007. doi: 10.1029/2006JE002831.

J. J. Plaut, G. Picardi, A. Safaeinili, A. B. Ivanov, S. M. Milkovich, A. Cicchetti, W. Kofman, J. Mouginot, W. M. Farrell, R. J. Phillips, S. M. Clifford, A. Frigeri, R. Orosei, C. Federico, I. P. Williams, D. A. Gurnett, E. Nielsen, T. Hagfors, E. Heggy, E. R. Stofan, D. Plettemeier, T. R. Watters, C. J. Leuschen, and P. Edenhofer. Subsurface Radar Sounding of the South Polar Layered Deposits of Mars. Science, 316:92-, April 2007. doi: 10.1126/science.1139672.

M. I. Richardson, R. J. Wilson, and A. V. Rodin. Water ice clouds in the Martian atmosphere: General circulation model experiments with a simple cloud scheme. Journal of Geophysical Research (Planets), 107:5064-+, September 2002. doi: 10.1029/2001JE001804.

M. D. Smith. The annual cycle of water vapor on Mars as observed by the Thermal Emission Spectrometer. Journal of Geophysical Research (Planets), 107:5115-+, November 2002. doi: 10.1029/2001JE001522.

A. L. Sprague, D. M. Hunten, R. E. Hill, B. Rizk, and W. K. Wells. Martian water vapor, 1988-1995. jgr, 101:23229-23254, $1996 . \quad$ doi: 10.1029/96JE02265.

A. L. Sprague, D. M. Hunten, L. R. Doose, R. E. Hill, W. V. Boynton, M. D. Smith, and J. C. Pearl. Mars atmospheric water vapor abundance: 1991 1999, emphasis 1998 1999. Icarus, 184:372-400, October 2006. doi: 10.1016/j.icarus.2006.05.021.

D. Titov. Water vapour in the atmosphere of Mars. Adv. Space Res., 29: 183-191, 2002.

D. V. Titov, V. I. Moroz, A. V. Grigoriev, J. Rosenqvist, M. Combes, J.P. Bibring, and G. Arnold. Observations of water vapour anomaly above Tharsis volcanoes on Mars in the ISM (Phobos-2) experiment. planss, 42: 1001-1010, November 1994. doi: 10.1016/0032-0633(94)90060-4.

D. V. Titov, W. J. Markiewicz, N. Thomas, H. U. Keller, R. M. Sablotny, M. G. Tomasko, M. T. Lemmon, and P. H. Smith. Measurements of the atmospheric water vapor on Mars by the Imager for Mars Pathfinder. jgr, 104:9019-9026, April 1999. doi: 10.1029/1998JE900046.

D.V. Titov. Spatial variations of the atmospheric water vapour on Mars from 
the ISM/Phobos-2 imaging spectrometry. Ann. Geophys., 15:C774, 1997.

M. Vincendon, Y. Langevin, F. Poulet, J.-P. Bibring, B. Gondet, D. Jouglet, and OMEGA Team. Dust aerosols above the south polar cap of Mars as seen by OMEGA. Icarus, 196:488-505, August 2008. doi: 10.1016/j.icarus.2007.11.034.

A.P. Zent and R.C. Quinn. Measurements of H2O adsorption under Mars-like conditions: Effects of adsorbent heterogeneity. JGR, 102:9085-9095, 1997.

A.P. Zent, R.M. Haberle, H.C. Houben, and B.M. Jakosky. A coupled subsurface boundary layermodel of water on Mars. JGR, 98:3319-3337, 1993. 


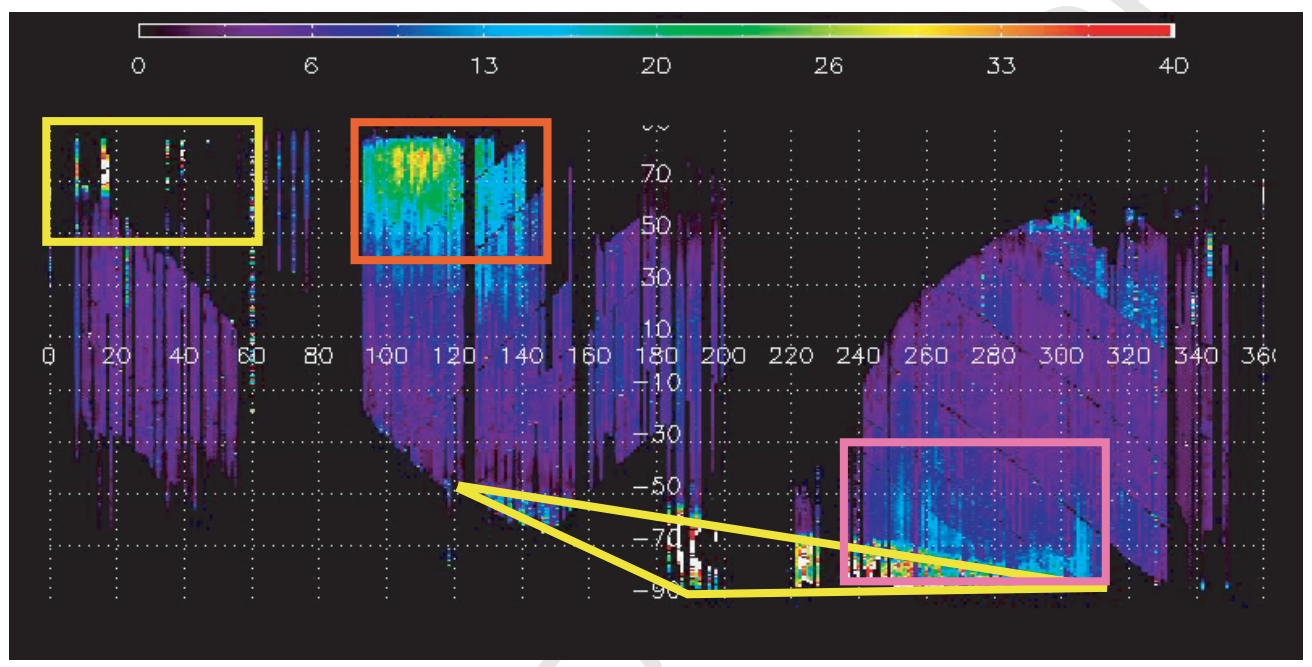

Fig. 1. Annual variability of water vapor as detected by OMEGA/Mars_Express for the first year of observations. Latitude is on ordinate and Ls is on abscissa. Our method is sensitive to the $\mathrm{CO}_{2}$ ice which alter our results, in this graph regions contaminated by $\mathrm{CO}_{2}$ ice have been kept and are identified by a yellow marker (receding ice caps). In the graphs is possible to identify the north summer sublimation period (red rectangle) and the south summer sublimation period (violet rectangle). 

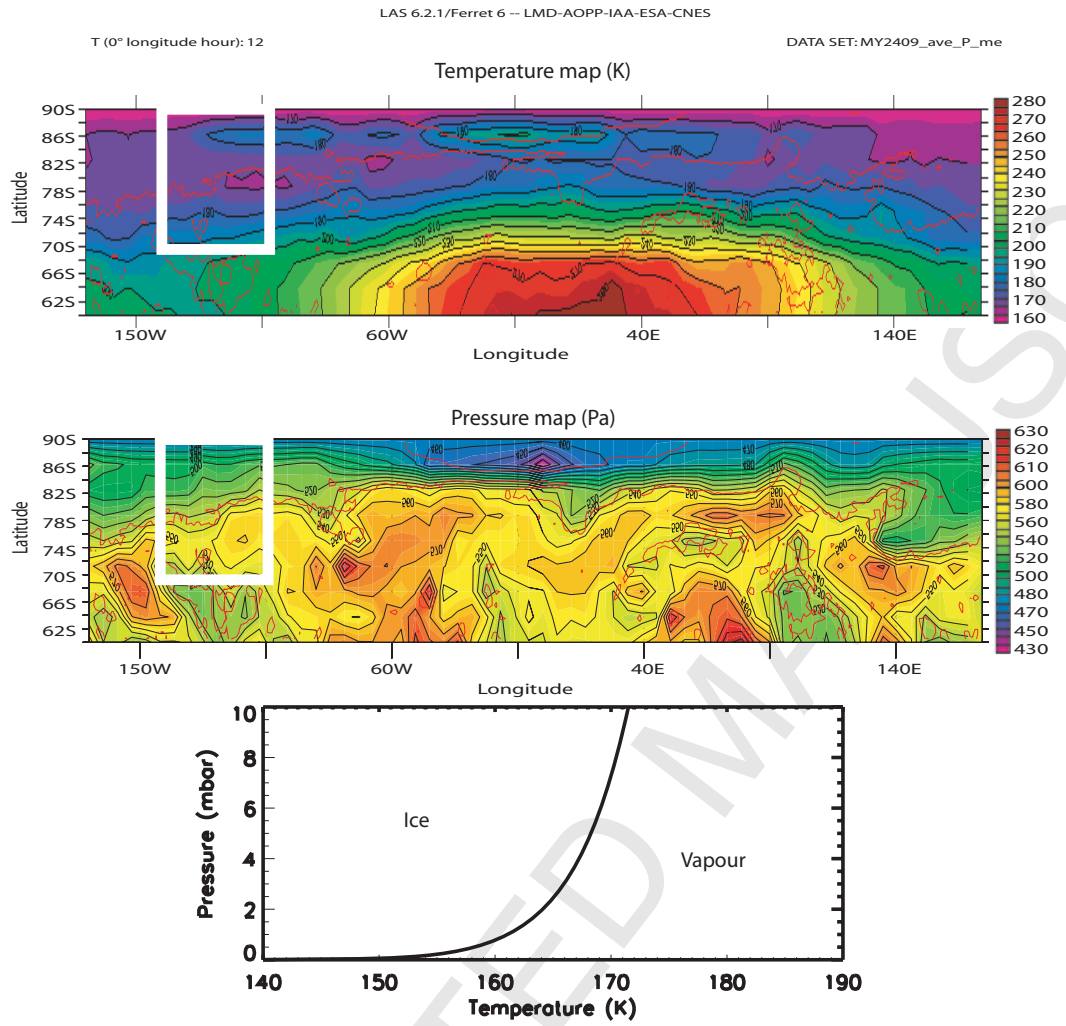

Fig. 2. The position of the 1983_1 orbit (a morning section) is delimited by a white rectangle, temperature varies in between $165^{\circ} \mathrm{K}$ and $190^{\circ} \mathrm{K}$ and pressure in between 4.8 and 6.1 mbar. Top: ground temperature estimation for a morning section as derived by the EMCD. Middle: ground pressure estimation for a morning section as derived by the EMCD. Bottom: water saturation Pressure/Temperature curve for $1 \mathrm{ppm}$ of water vapor. The morning sections are in between the water saturation point. 


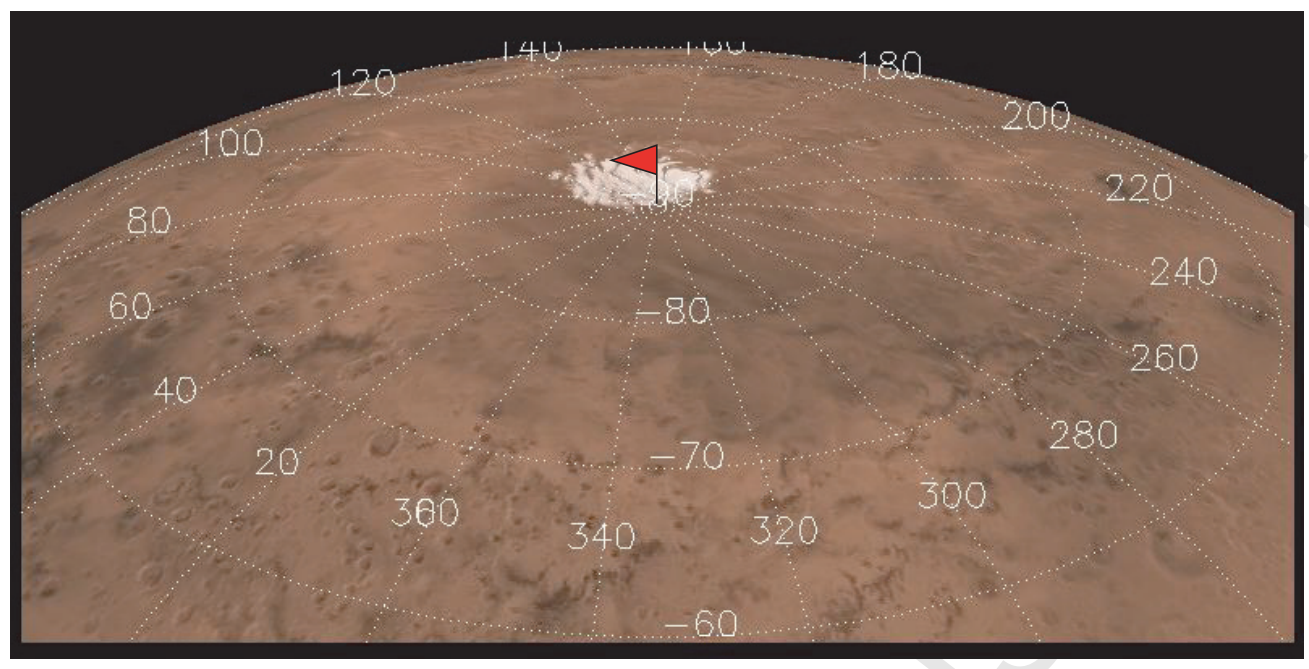

Fig. 3. Mars has seen by the Sun for $\mathrm{Ls}_{\mathrm{S}}=250^{\circ}$. The South Pole is entirely as far north as $60^{\circ} \mathrm{S}$.

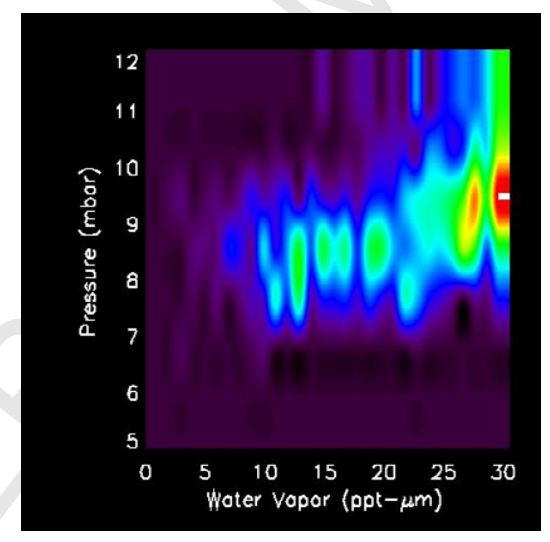

Fig. 4. This graphic shows the dependence of the water vapor value normalized to the retrieved pressure compared to the pressure. A constant value can be retrieved for values under $20 \mathrm{ppt}-\mu$, which demonstrates that the retrieved pressure through the $2.0 \mu \mathrm{m}$ band has been accurate enough to do not introduce a pressure variability in the water vapor. Values above $10 \mathrm{mbar}$ and above $20 \mathrm{ppt}-\mu \mathrm{m}$ are associeted with the presence of $\mathrm{CO}_{2}$ ice which contaminates both bands, these data must be then discarded. 

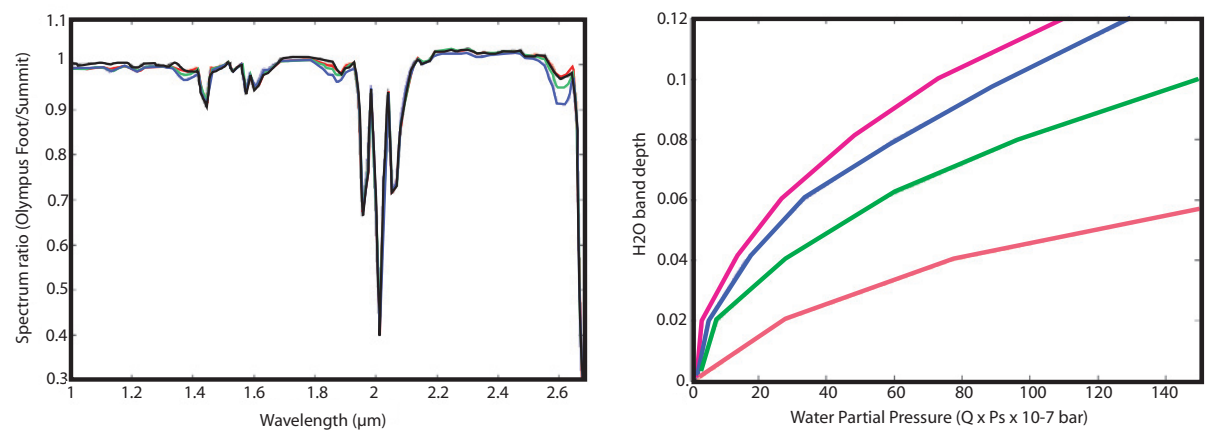

Fig. 5. On the left some example of spectra for different mixing ratios of water vapor: $150 \mathrm{ppm}$ (red), $300 \mathrm{ppm}$ (green) and $600 \mathrm{ppm}$ (blue). On the right the curves of growth of the $2.6 \mu \mathrm{m} \mathrm{H}_{2} \mathrm{O}$ band, calculated for different values of the surface pressure (Ps). From right to left : Ps 1.4, 4.0, 7.5 and 10.0 mbar. The abscissa is the product of the surface pressure and the $\mathrm{H}_{2} \mathrm{O}$ mixing ratio, i.e. the $\mathrm{H}_{2} \mathrm{O}$ partial pressure at the surface. The ordinate is the depth of the water band. The figures are taken from Melchiorri et al. (2007) 


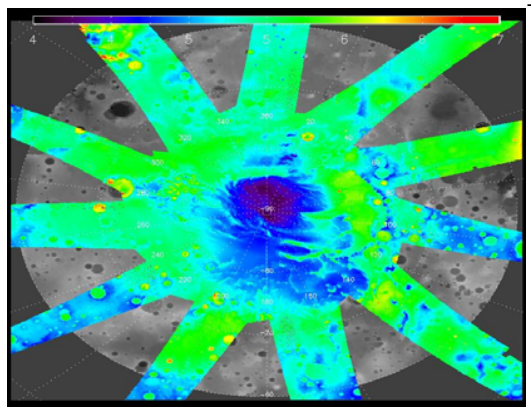

range form 4 to 7 mbar

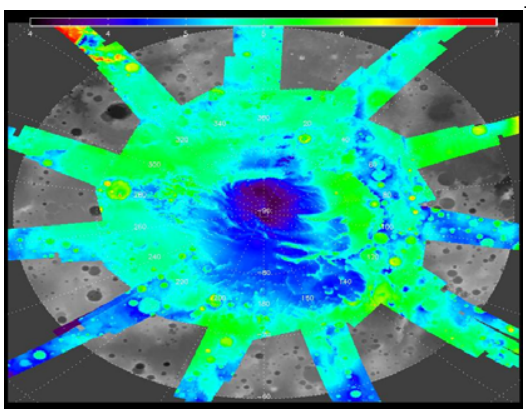

range from 4 to 7 mbar

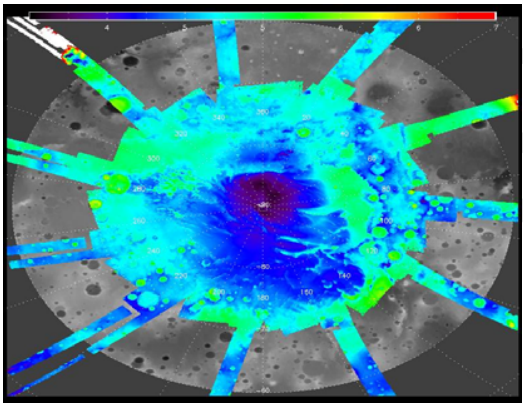

range from 4 to7 mbar
Ls 250

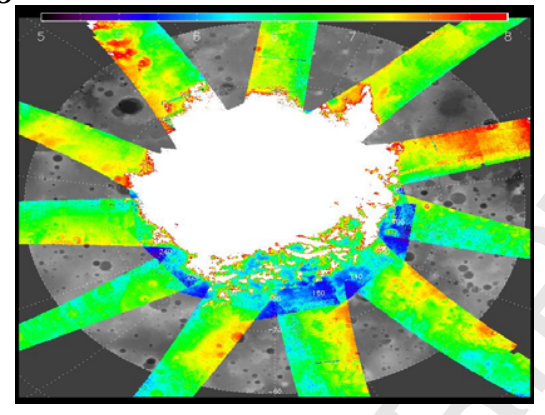

range from 5 to 8 mbar

Ls 260

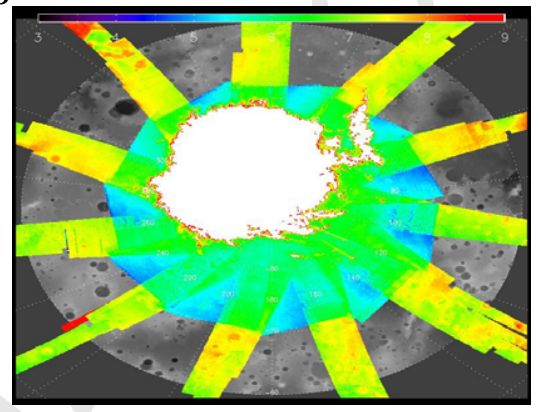

range from 3 to 9 mbar

Ls 270

Fig. 6. Ground pressure value for $\mathrm{Ls}=250^{\circ}, 260^{\circ}$ and $270^{\circ}$ on the South Pole, as derived by the EMCD (left) and as derived as OMEGA data (right). The presence of $\mathrm{CO}_{2}$ ice alter the detected value in the OMEGA data retrieval and is shown as a clear enhancement of the value, the icy region has been shown in white in the right figures. Orbits start close to the Pole during the morning and continue toward the equator in the afternoon. Values closer to the South Pole (morning) in the OMEGA data (right figures) are lower than the one expected from the EMCD (left figure). Moreover values from the OMEGA data closer to $60^{\circ} \mathrm{S}$ are higher than the EMCD one. 

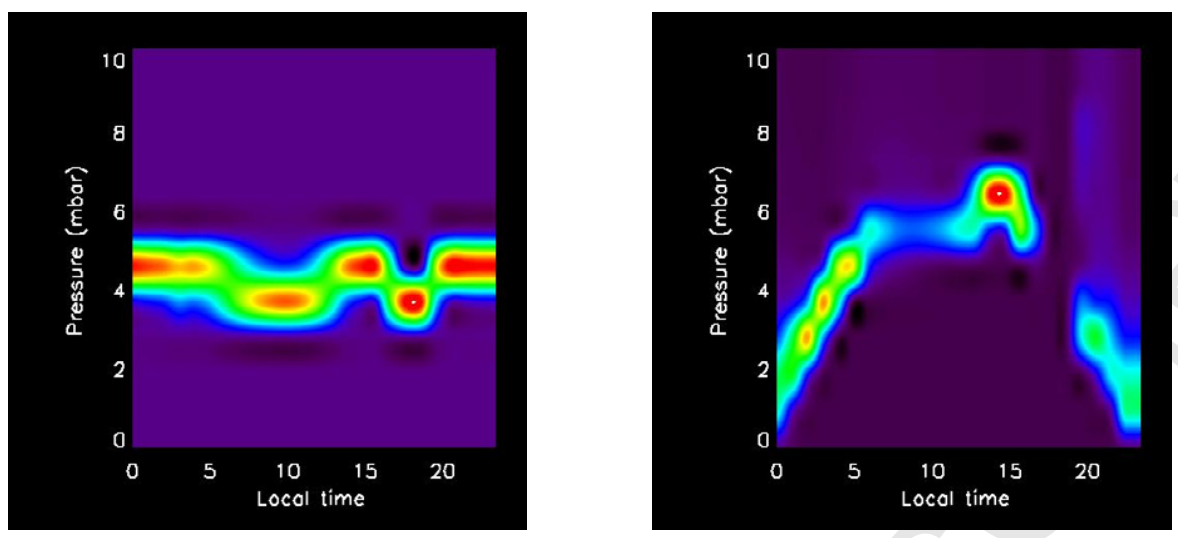

Fig. 7. Comparison between Pressure distribution over local time for the whole period $\mathrm{LS}=250^{\circ}-270^{\circ}$ as derived by EMCD (left) and as retrieved through the $2.0 \mu \mathrm{m} \mathrm{CO}_{2}$ band (right). A clear daily variability is noticeable in the right panel.

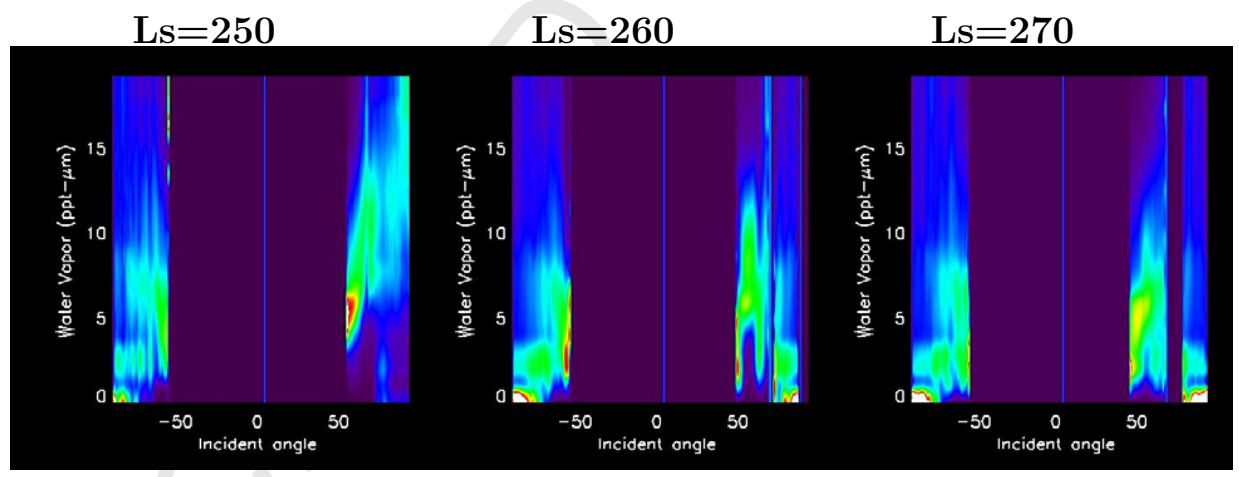

Fig. 8. water vapor distribution over the incidence angle for the three $\mathrm{Ls}=250^{\circ}, 260^{\circ}$ and $270^{\circ}$. Negative values indicate morning values. An increase of the water vapor is visible in all the three images, from $-90^{\circ}$ to $+90^{\circ}$ (more evident in $\mathrm{Ls}=250^{\circ}$ and less evident for $\mathrm{Ls}=270^{\circ}$ ). This shows a non correlation between the water vapor variability and the incidence angle, which implies that scattering is not the main cause of the water vapor variability. 


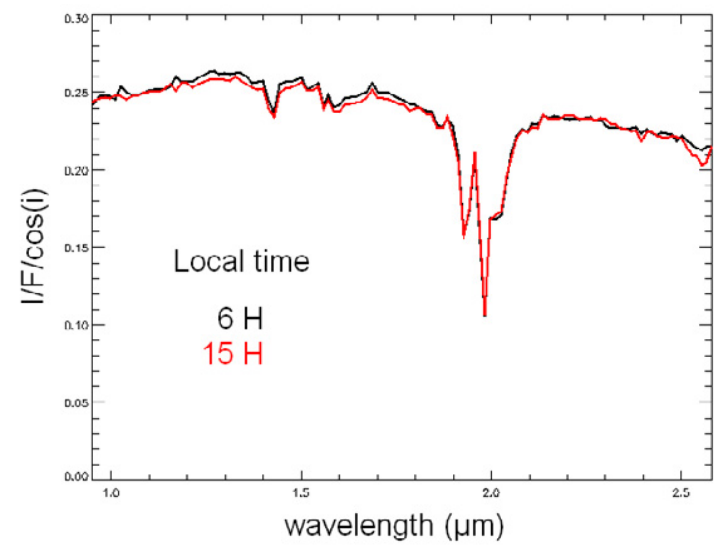

Fig. 9. Spectral Comparison of a morning and an evening section. Spectra have been normalized to the incidence angle. No variability is detected but for the water bands.
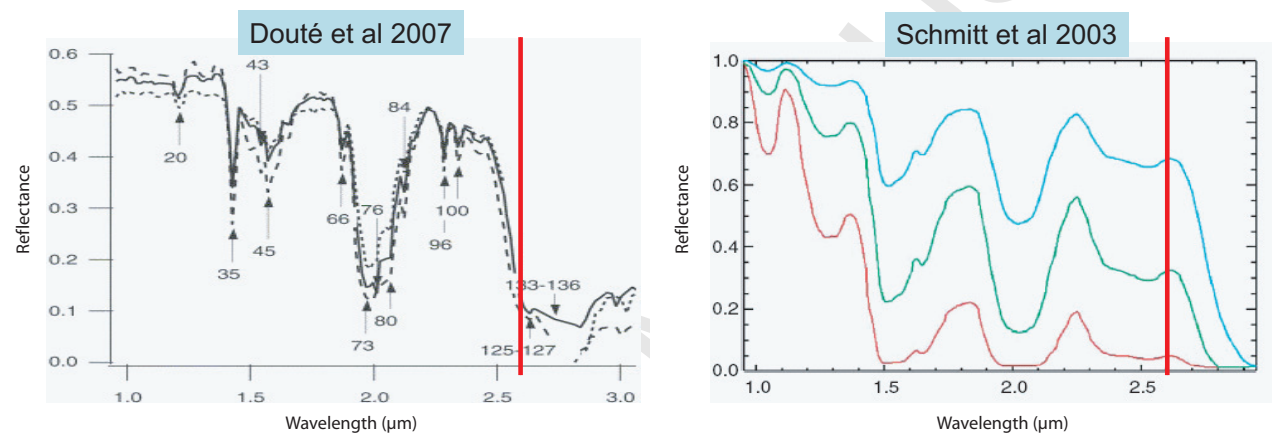

Fig. 10. The $2.6 \mu \mathrm{m}$ water vapor band can be contaminated by the presence of $\mathrm{CO}_{2}$ ice (on the left) (Dout et al., 2007) or by small grains of water ice (on the right) .

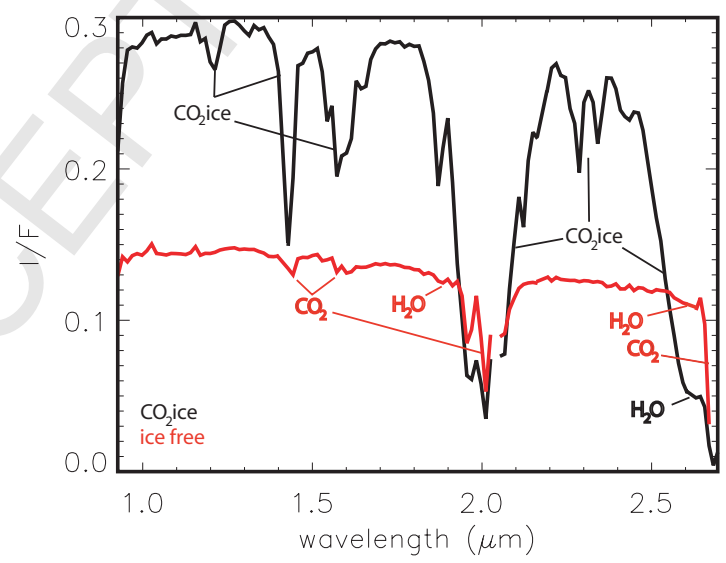

Fig. 11. Comparison of spectra from a region covered by $\mathrm{CO}_{2}$ ice (black) and a region without (red); the presence of $\mathrm{CO}_{2}$ ice influences the $2.6 \mu \mathrm{m}$ band. 


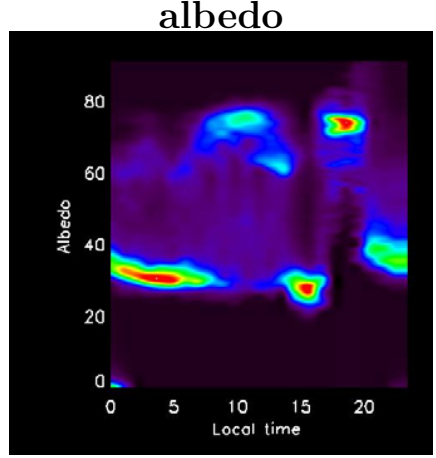

water vapor

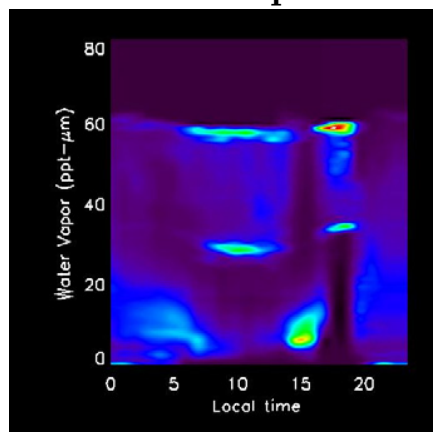

water vapor zoom

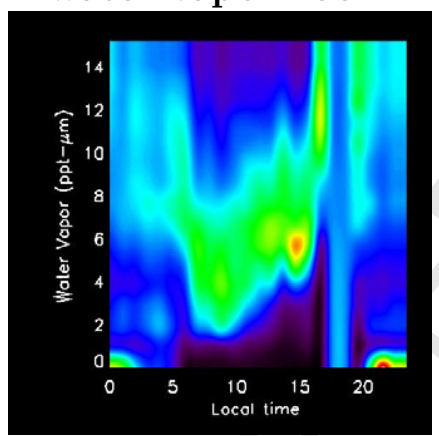

Ls 250

Histogram distribution for $4 \mathrm{am}$

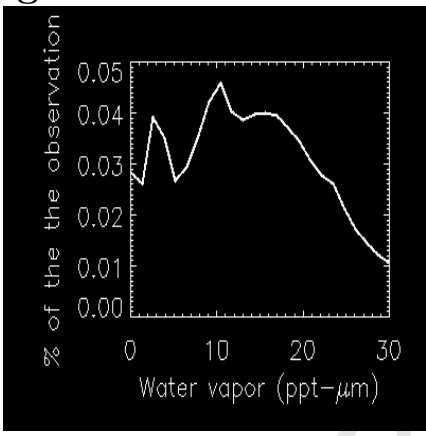

Histogram distribution for 10am

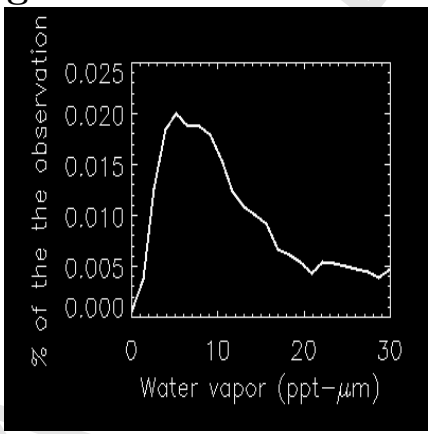

Histogram distribution for $4 \mathrm{pm}$

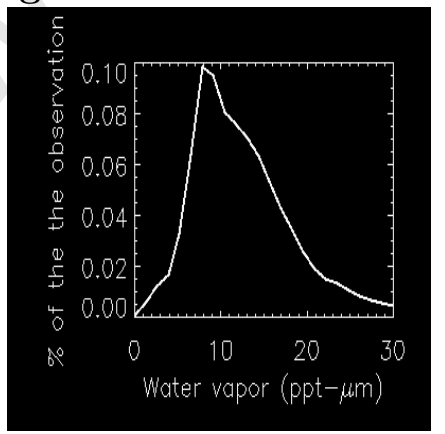

Fig. 12. On the left: water vapor and albedo distribution for the period $L s=250^{\circ}$. Color table shows the ratio of how many observations obtained south of $60 \mathrm{~S}$ have a selected value at a given local time; each of these values are divided by the total number of observations per each local time. On the right: histograms of the water vapor distribution for selected local times (4am, 10am and 4pm). The albedo presents a constant value of 0.35 , with a little decreasing slope with time (inside the error bar). Higher values after $8 \mathrm{pm}(\sim 0.4)$ suggest the possible presence of ice on the ground, which, otherwise, has not been spectrally detected. The higher values from $7 \mathrm{am}$ to $1 \mathrm{pm}$ is due to the presence of the $\mathrm{CO}_{2}$ ice present in the ice cap. water vapor can be divided in three groups: values ranging between 0 and $15 \mathrm{ppt}-\mu \mathrm{m}$, values around $30 \mathrm{ppt}-\mu \mathrm{m}$ and values above $30 \mathrm{ppt}-\mu \mathrm{m}$. The first group (between $5 \mathrm{am}$ and $4 \mathrm{pm}$ ) increases and it is noticeable that values under $2 \mathrm{ppt}-\mu \mathrm{m}$ in the morning and then $4 \mathrm{ppt}-\mu \mathrm{m}$ in the afternoon are not detected, which is the case for the early morning and the late afternoon. The second group seems to be correlated with the regions close to the $\mathrm{CO}_{2}$ ice (but still free of ice), which may imply that ice cap is a main source of $\mathrm{H}_{2} \mathrm{O}$. The third group is a detection of $\mathrm{CO}_{2}$ ice, these values should not be interpreted as water vapor. This gloup is highly correlated with high albedo regions (from $50 \%$ to $80 \%$, due to ice), which confirm the sensitivity of our method to the $\mathrm{CO}_{2}$ ice. 


\section{Ls 260}

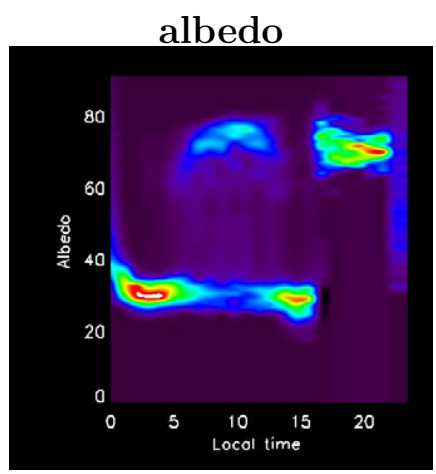

Histogram distribution for $4 \mathrm{am}$
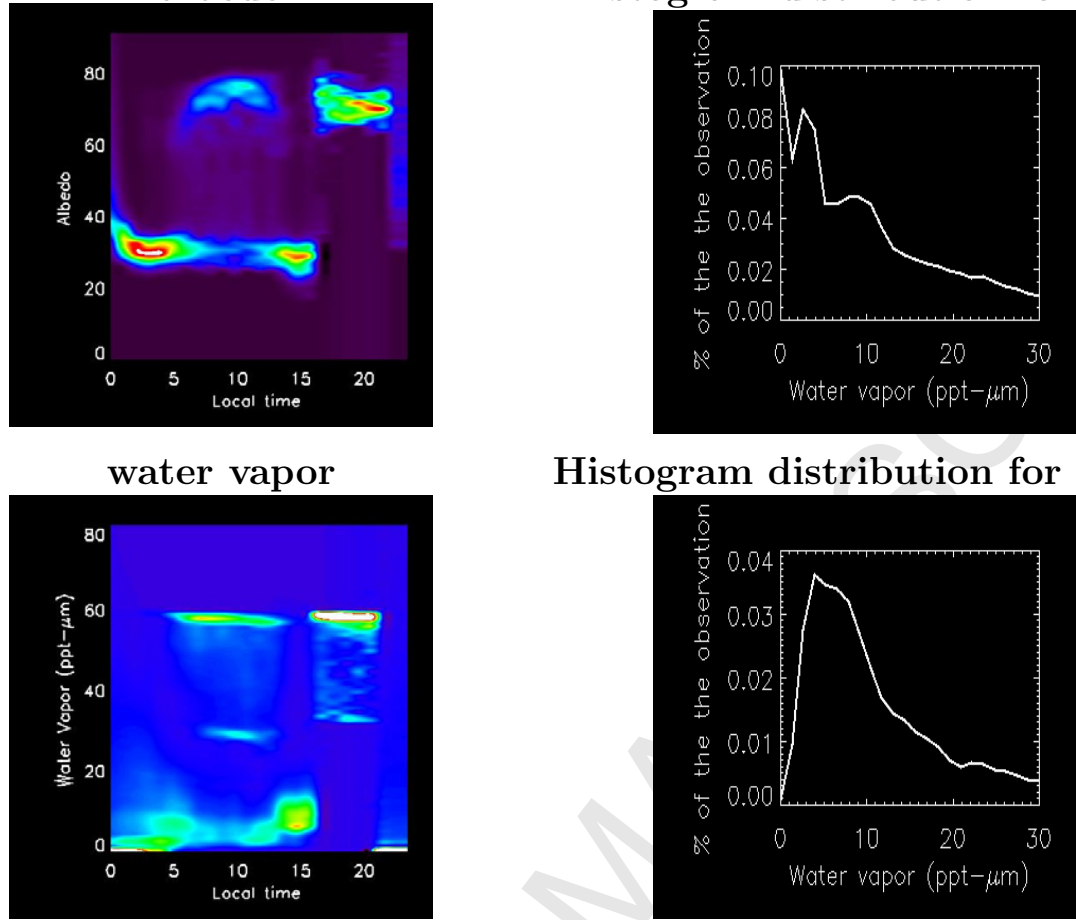

Histogram distribution for 10am
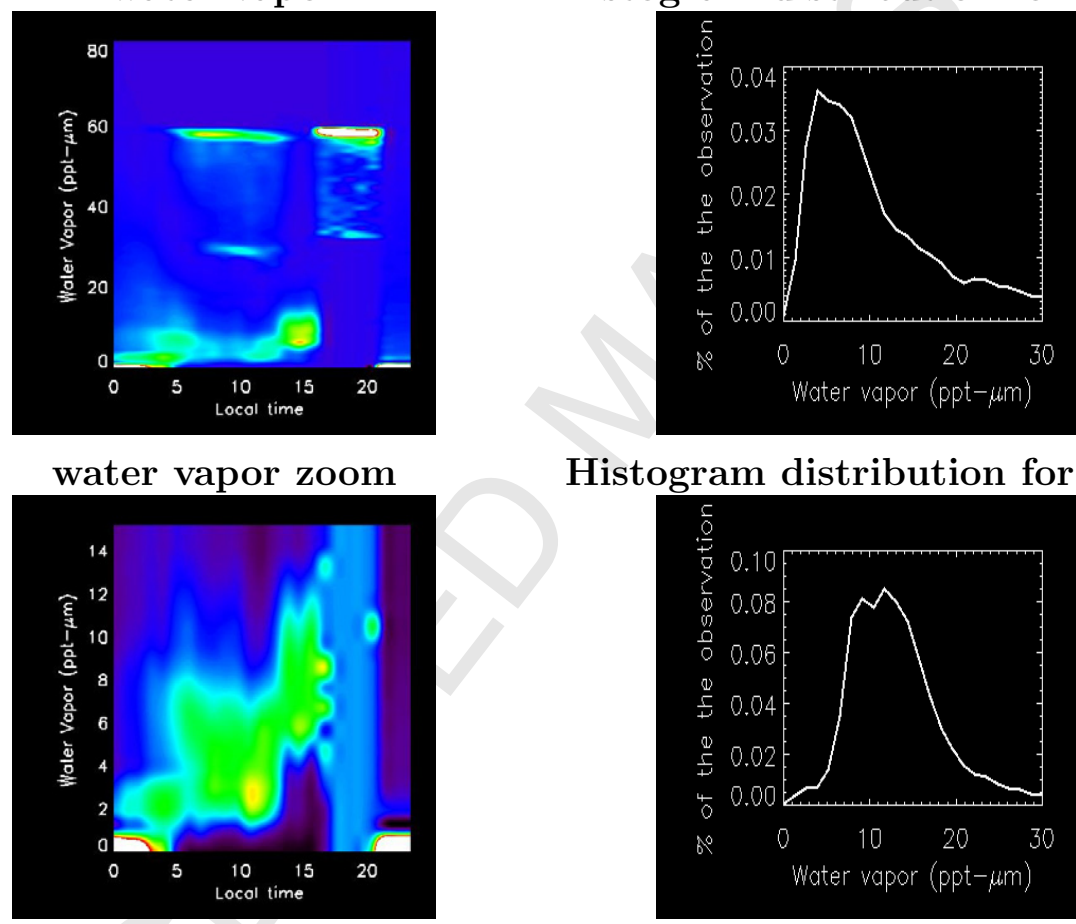

Histogram distribution for $5 \mathrm{pm}$

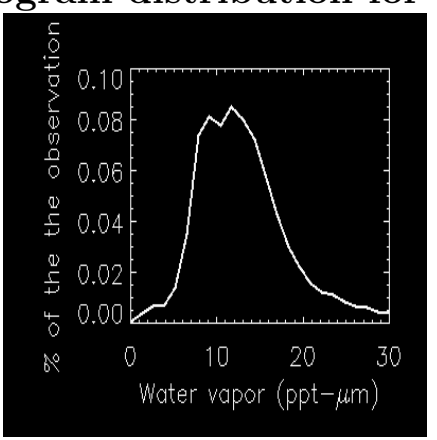

Fig. 13. As for $\mathrm{Ls}=250^{\circ}$, but data represent $\mathrm{Ls}=260^{\circ}$. Histograms of the water vapor show selected local times (4am, 10am and 5pm). The albedo presents a constant value of 0.35 ; a small increase is detected in the morning $(\sim 38 \%)$. The higher values from $7 \mathrm{am}$ to $12 \mathrm{pm}$ is due to the presence of the $\mathrm{CO}_{2}$ ice, associated with observations over the ice cap. Water vapor second group $(30 \mathrm{ppt}-\mu \mathrm{m})$ shows an increase for values between $4 \mathrm{pm}$ and $8 \mathrm{pm}$, this should be taken very carefully because it could be due to a very small contamination of $\mathrm{CO}_{2}$. 


\section{Ls 270}

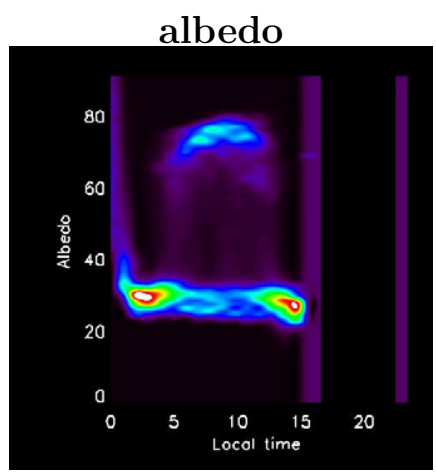

Histogram distribution for $4 \mathrm{am}$

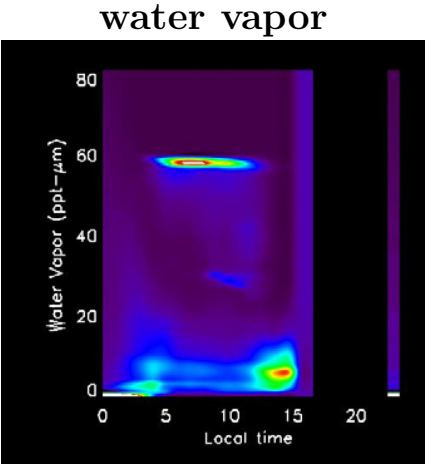

Histogram distribution for 10am
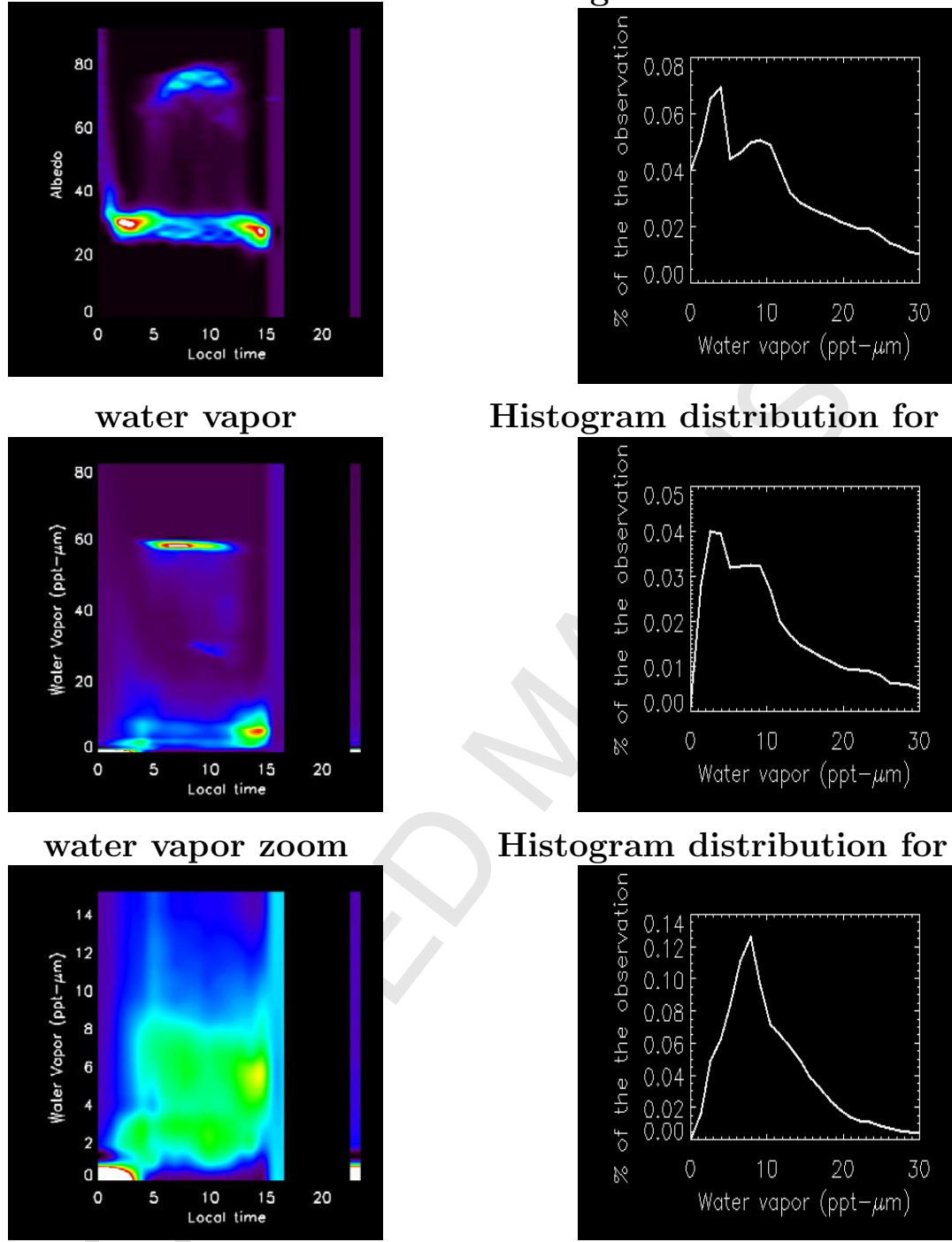

Histogram distribution for $3 \mathrm{pm}$

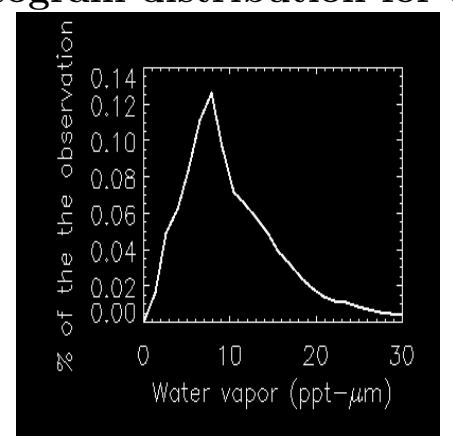

Fig. 14. As for $\mathrm{Ls}=250^{\circ}$, but data represent $\mathrm{Ls}=270^{\circ}$. Values range only between $12 \mathrm{am}$ to $4 \mathrm{pm}$. The first group of water vapor (ranging between 0 to $15 \mathrm{ppt} \mu \mathrm{m}$ ) shows a quasi constant value over time (between $2 \mathrm{am}$ to $3 \mathrm{pm}$ ). A small increase is visible (but within the error bar) between 1am to $3 \mathrm{am}$. Low values are present only in the early morning (12am - 4am). 

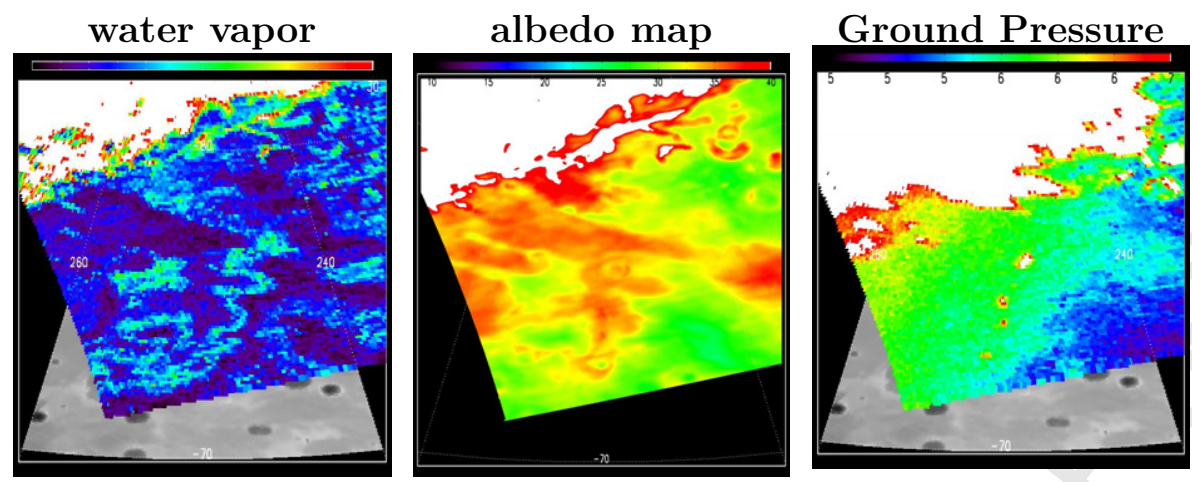

Fig. 15. This orbit shows a typical enhancement for the morning sections. It is extremely delimited, but it doesn't depend on altimetry nor ground pressure. There is a good correlation with the boundary of regions with different albedo, but not with the albedo itself.
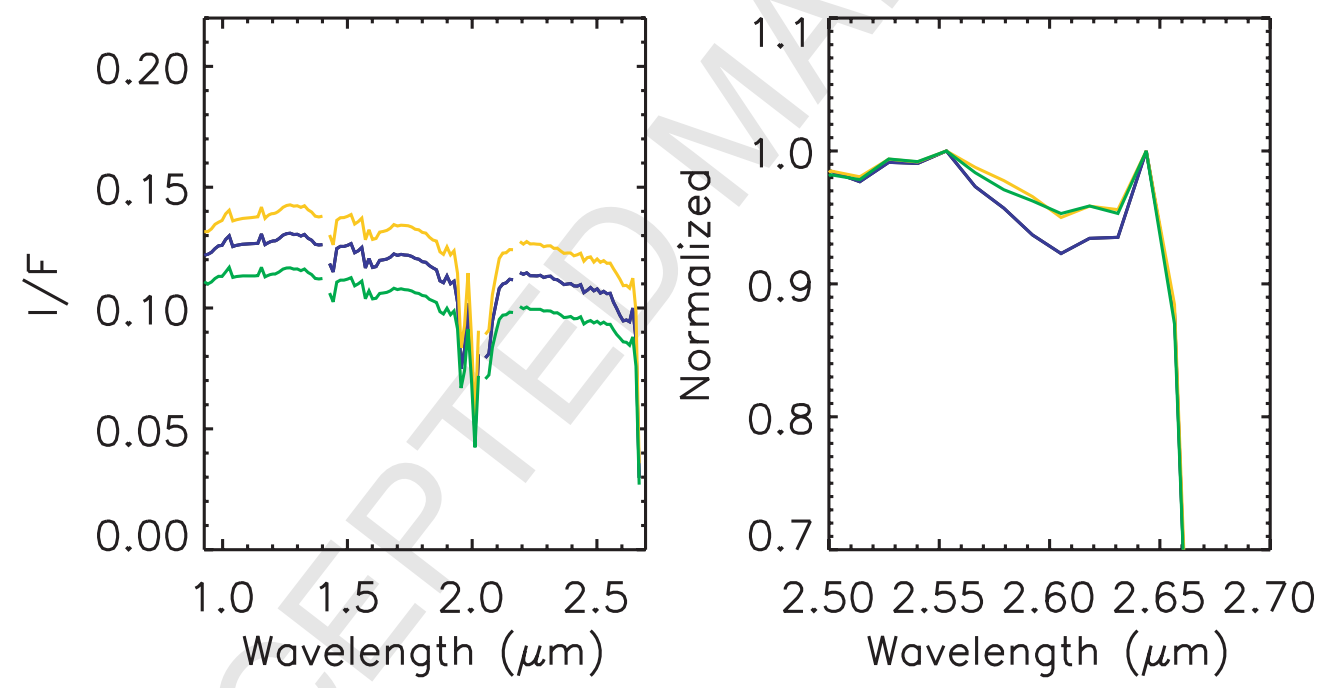

Fig. 16. These are the mean spectra retrieved from a bright region (yellow), water vapor enhancement (blue) and dark region (green). Water vapor region is in between the previous regions and shows a prominent water vapor band. On the right a zoom of the $2.5-2.7 \mu \mathrm{m}$ region of normalized spectra (at $2.5 \mu \mathrm{m}$ ), showing the enhancement of water vapor (blue) compared to the dryer regions (yellow and green, spectra partially overlap). Spectra on the left have not been corrected by the incidence angle. 